\title{
Intercâmbio Cultural Aproxima Brasil e México
}

\section{Cultural Exchange Approximates Brazil and Mexico}

Por meio de convênio assinado no início do ano passado entre a Universidade de São Paulo (USP) e a Universidade Autônoma do México (UNAM) foi possível realizar um projeto na área de artes cênicas que reuniu profissionais de ambas as universidades. O projeto resultou, especialmente, na produção de dois espetáculos, apresentados tanto no Brasil como no México, montados por grupos de alunos dos dois países e acompanhados de um diretor mexicano e de um diretor brasileiro.

Convidados a contar suas experiências durante o processo de montagem e apresentações que fizeram parte desse intercâmbio, alguns atores concederam entrevista à Revista Cultura e Extensão USP, que traz também nesta reportagem informações sobre a troca de conhecimentos acadêmicos e culturais estabelecida entre as duas universidades, além de falar dos desafios encontrados em questões que vão além do teatro universitário e da diferença de idiomas, costumes e percepção social nos contextos do Brasil e México.

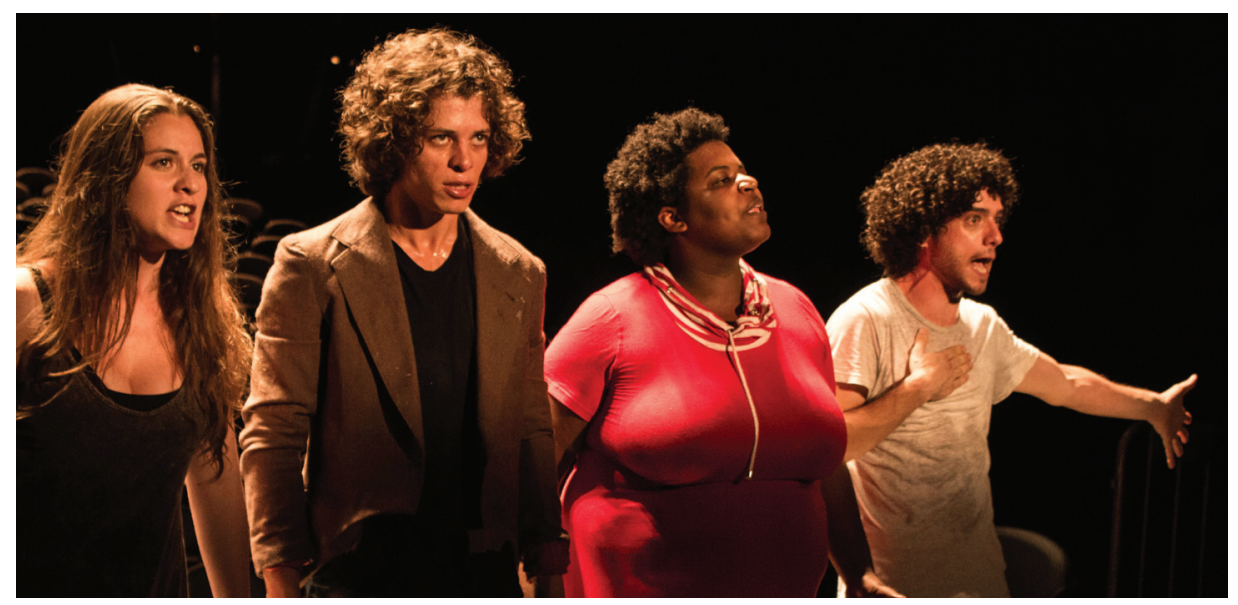

\section{Marina Salles}

Universidade de São Paulo. Escola de Comunicações e Artes, São Paulo, Brasil
Figura 1 - $O$ espetáculo La pasión en la materia é resultado da colaboração entre o diretor mexicano Alberto Villarreal e estudantes de teatro da USP. 


\section{TEATRO UNIVERSITÁRIO}

Palco de difícil demarcação, o teatro universitário abarca diferentes conceitos. No caso específico da Universidade de São Paulo, prefere-se tomá-lo em sentido amplo, que vai além do "universitário" e recai sobre outra definição: a de teatro vocacional. Segundo Ferdinando Martins, diretor do Teatro da USP (TUSP), "teatro vocacional é aquele que a pessoa procura porque tem uma vocação, o desejo de fazer teatro, e como não há uma definição muito rígida de teatro universitário, pode-se pensar que esse é um teatro feito por estudantes de artes cênicas ou por qualquer universitário".

A partir de outras referências, o diretor do Centro Universitário de Teatro (CUT) da UNAM, Mario Espinosa, explica o que entende pelo termo no contexto do trabalho que desenvolve. De acordo com o teatrólogo, na UNAM o teatro universitário abrange muitas categorias. "Uma delas é a educação média, que inclui escolas da rede pública e particular vinculadas de alguma forma à universidade; seguida do grupo de universitários de outras carreiras que não se relacionam com o teatro, mas que participam de oficinas oferecidas em seus campi. Por último, existe também uma terceira categoria, que é a dos estudantes de teatro e se divide em: alunos de teatro que trabalham com alunos de teatro, ex-alunos que dirigem alunos e alunos dirigidos por seus professores".

\section{PERSONAGENS DESSE ENREDO}

Independente das terminologias adotadas em cada país, Ferdinando deixa claro que o convênio entre a UNAM e a USP é mais específico e se destina aos alunos de artes cênicas de ambas as instituições. "Nosso objetivo é trabalhar com os estudantes visando uma continuidade de ações que possa desenvolver a própria área de artes cênicas nas duas universidades”.

Para participar do intercâmbio cultural, os alunos foram selecionados por meio de um workshop. O resultado foi a composição de duas obras teatrais, feitas em conjunto entre profissionais do México e do
Brasil. A seguir, os alunos contam porque, para eles, o sentimento em relação ao teatro universitário ultrapasa limites de significado:

\section{MARCO GUAGNELLI}

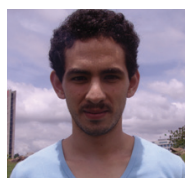

Minha necessidade de estudar teatro é pessoal, uma necessidade de entender a mim mesmo. Acredito que representar os personagens seja a maneira que encontrei de estar mais próximo das pessoas e poder me relacionar com elas, uma vez que assumo outras personalidades e começo a entendê-las. Agora, saindo da universidade, nos damos conta do que de fato é o teatro e dos riscos que precisamos assumir para enfrentar essa carreira.

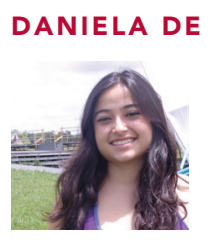

LOS RÍOS

Sempre estive muito ligada às atividades artísticas: fazia aulas de piano, canto, acordeão, dança... E quando me vi no momento de escolher uma carreira pensei em fazer licenciatura em canto, mas meus pais diziam: "Arte? Melhor você escolher outra coisa". Então, fui estudar Medicina, até que finalmente decidi que não pertencia àquele mundo e que não podia continuar vivendo daquela forma. Comecei a buscar e logo descobri que o teatro podia ser uma opção para mim. Foi a experiência mais incrivel da minha vida, porque você aprende a crescer internamente para poder alimentar e entender o exterior.

\section{SOL SÁNCHEZ}

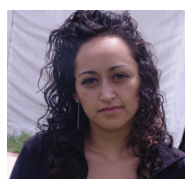

Eu devo tudo ao teatro universitário. Minha família não teria condições de pagar um curso como esse que faço no CUT (Centro Universitário de Teatro da UNAM). Fiz os exames para ingressar por três vezes, até que, quando entrei, decidi que ia ser atriz de qualquer maneira, fosse no México, fosse nas ruas ou em qualquer outro lugar. É comum que ao entrar no curso estejamos tomados de muita ilusão, mas essa é também a magia do teatro.

\section{DARÍLIA LILBÉ}

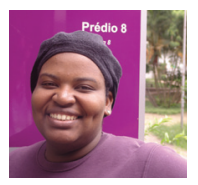

Eu escolhi fazer teatro por acaso, sou mineira e vim para São Paulo tem uns dez anos. Minha cidade era pequenininha e foi um choque cultural muito grande chegar aqui, 
então, comecei a fazer teatro para perder a timidez. Depois, trabalhei no ramo de tecnologia, enquanto fazia teatro também, até prestar a EAD (Escola de Arte Dramática da USP), o que mudou a minha vida no sentido de assumir o teatro como uma carreira profissional. Antes era mais uma coisa amadora e por mais que eu tentasse viver só de teatro, eu não tinha recursos financeiros para isso.

\section{MODELOS DE CADA ESCOLA}

Mario Espinosa diz que as escolas de cada uma das universidades têm características em comum, sendo o Centro Universitário de Teatro (CUT) mais parecido à Escola de Arte Dramática (EAD) e o Colégio de Literatura Dramática e Teatro ao Departamento de Artes Cênicas (CAC) da USP.

Comparando os cursos, um detalhe que chama a atenção é o fato de ambas as escolas dedicadas a formar atores não concederem ao aluno um diploma de graduação. O diretor do CUT conta que as carreiras artísticas sofreram processos de estruturação diferentes das demais, sendo comum, tanto na Europa quanto nos Estados Unidos, os estudantes não se graduarem. De acordo com ele, apesar dos alunos saírem bem preparados do centro e conseguirem colocações no mercado de trabalho, as limitações estão no fato de, hoje em dia, especialmente

CURSOS DE TEATRO NA UNAM

CURSOS DE TEATRO NA USP

\begin{tabular}{|c|c|c|c|}
\hline \multicolumn{2}{|r|}{ Centro Universitário de Teatro (CUT) } & \multicolumn{2}{|r|}{ Escola de Arte Dramática (EAD) } \\
\hline " & $\begin{array}{l}\text { O curso é vinculado à Coordenação de Difusão } \\
\text { Cultural da UNAM e não equivale a uma } \\
\text { graduação. }\end{array}$ & " & $\begin{array}{l}\text { Curso de segundo grau ministrado no período } \\
\text { noturno. }\end{array}$ \\
\hline$"$ & Formação de atores profissionais. & " & Formação de atores em nível técnico. \\
\hline$"$ & Período integral. Duração de quatro anos. & " & Duração de quatro anos. \\
\hline$"$ & 16 vagas. & " & 20 vagas. \\
\hline " & $\begin{array}{l}\text { O processo de seleção é realizado de acordo } \\
\text { com as normas do centro. }\end{array}$ & $"$ & $\begin{array}{l}\text { Edital de ingresso é independente do vestibular } \\
\text { da Universidade de São Paulo. }\end{array}$ \\
\hline
\end{tabular}

Colégio de Literatura Dramática e Teatro

" Curso superior oferecido na Faculdade de Filosofia e Letras da UNAM, que possui atualmente 600 alunos.

" Duração mínima de quatro anos.

" Licenciatura está focada nas seguintes áreas do conhecimento: Desenho e Produção, Atuação, Direção, Dramaturgia e Teatrologia.

" Para ingressar na faculdade é necessário atender os requisitos estabelecidos pela UNAM.

\section{Departamento de Artes Cênicas (CAC)}

" Oferece graduação e pós-graduação, sendo o curso superior ministrado em período integral.

" Duração mínima de quatro anos.

" Bacharelado, com habilitação em Cenografia, Direção Teatral, Interpretação Teatral e Teoria do Teatro; ou licenciatura em Educação Artística, com habilitação em Artes Cênicas.

" Anualmente são abertas 15 vagas, preenchidas por exame de seleção da FUVEST, acompanhado de provas específicas. 
no México, ser exigida a graduação para a continuidade de estudos acadêmicos ou para dar aulas. Espinosa acrescenta que uma alternativa é recorrer à lei que permite provar a "aquisição de conhecimentos", segundo a qual as pessoas são capazes de aprender determinados assuntos de forma autônoma, ou seja, usando a mesma prerrogativa dos autodidatas.

Atualmente, de acordo com Espinosa, "o que a UNAM tem tentado fazer é instituir um processo muito similar ao que se estabeleceu na Alemanha e na França, que optaram pela titulação, meta da universidade para 2014”. Ainda segundo o diretor do CUT, na Europa, desde 2010, implantou-se o processo Bolonha, cujo objetivo foi reorganizar graus e diplomas do ensino superior a fim de facilitar seu reconhecimento e ampliar oportunidades de mobilidade frente a outras instituições da comunidade europeia.

Sobre os cursos oferecidos na USP, Darília Lilbé comenta que, quando procurou a $\mathrm{EAD}$, ter uma graduação não era seu principal objetivo, mas que hoje faria o CAC também, caso pudesse destinar um tempo para se preparar para o vestibular. De acordo com a estudante, "apesar de funcionar como uma escola técnica, a EAD pode ser considerada uma espécie de especialização - procurada tanto por gente que já se formou, tem experiências fora do país ou fez pós-graduação, quanto por aqueles que veem na FUVEST uma barreira para ingressar na Universidade”. Para a atriz, a importância do teatro universitário está ligada à necessidade de instrumentalização do artista e às vantagens de se conviver com um grupo que tem interesses em comum. "É importante dar ferramentas para o ator conseguir comunicar o que está latente nele e poder partilhar de um ambiente em que encontra pessoas que querem pesquisar. Muitos de nós temos coisas para dizer e não sabemos como; essa é também uma forma de nos reconhecermos", argumenta.

\section{INTERCÂMBIO ENTRE AS UNIVERSIDADES}

Valer-se de experiências diferentes que se cruzam em determinados pontos: o intercâmbio não tem outro papel senão permitir às duas universidades trocar conhecimentos a respeito de suas deficiências e qualidades aprimoradas ao longo dos anos. Para Mario Espinosa, diretor do CUT, é muito importante passar por esse tipo de experiência, como a que permitiu que atores brasileiros tivessem contato com um diretor mexicano, e os atores mexicanos, por sua vez, trabalhassem com um diretor brasileiro. Segundo ele, "em cada lugar temos os nossos costumes, nossa maneira de fazer as coisas, o que nos obriga a ser mais flexíveis nesses contextos, criar outra visão e tomar atitudes de maneira distinta”. Ainda na opinião do diretor, essa é uma excelente oportunidade para minimizar preconceitos que existem entre nações latino-americanas e promover uma união de fato.

Sobre as trocas que vão além da construção dos espetáculos, Ferdinando pondera que as universidades se completam, sendo que a UNAM se desenvolveu em áreas diferentes da USP, e vice-versa. Um exemplo claro diz respeito à infraestrutura da Universidade de São Paulo. Para o diretor do TUSP, “a UNAM tem um fazer teatro muito mais avançado que o nosso, digamos, em cenografia, em produção e em recursos humanos e estrutura física, inclusive. $\mathrm{Na}$ USP, por exemplo, temos duas pessoas para cuidar de figurino e lá tem toda uma equipe para isso. Eles têm uma oficina de marcenaria própria para cenografia, coisa que a gente não tem. É uma verdadeira máquina de produção! Além disso, a UNAM tem 14 salas de teatro e nós temos apenas duas, então, nesse sentido existe um encaixe".

Em contrapartida, a UNAM não oferece pós-graduação em Teatro, sendo que seus profissionais ficam limitados a realizar estudos em áreas afins ou a ter que se deslocar para outros países com o objetivo de cursar mestrado ou doutorado. Segundo Mario Espinosa, "a Universidade tem especializações em Artes Visuais, Estética, História da Arte e Letras, mas não especificamente em Teatro, então, quem se dedica a fazer teatro acaba não ficando na UNAM". De acordo com ele, o objetivo da Universidade é estruturar um programa que colabore para a formação de mestres e 


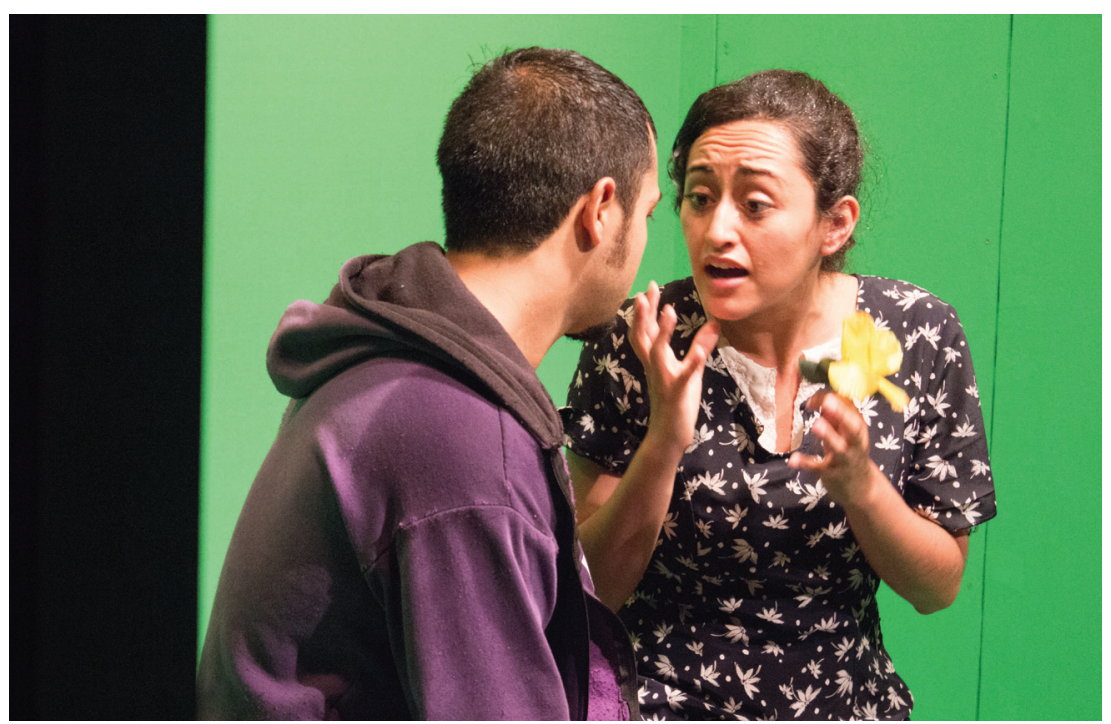

Figura 2 - Rodrigo S.M. conta a história vivida por Macabea, de Clarice Lispector, tratando com beleza e simplicidade a personagem que também conquistou os mexicanos.

doutores, aproveitando a experiência que a USP tem na área. A médio prazo, o diretor do CUT espera que as gerações de artistas ativos na UNAM possam desenvolver suas capacidades formais de investigação e pesquisa, ao mesmo tempo em que seguem criando. "Buscamos o perfil do pesquisador que faz de seus processos criativos seus processos de análise formal, e esse lado não organizamos academicamente, apesar de acontecer na prática”.

\section{RODRIGO S.M. E LA PASIÓN EN LA MATERIA}

Selecionados a partir da oportunidade que se criou com o convênio de cooperação acadêmica entre as universidades, os atores e atrizes das escolas de teatro da UNAM e da USP trabalharam sob supervisão dos diretores Alberto Villarreal e Pedro Mantovani, respectivamente.

Alberto Villarreal é licenciado em Literatura Dramática e Teatro pela UNAM e possui mais de quarenta produções em seu currículo. Nascido em 1977, o autor e diretor de La pasión en la materia, obra interpretada pelo grupo de estudantes brasileiros, é um dos nomes de maior destaque do teatro mexicano recente. Pedro Mantovani, por sua vez, estudou Filosofia na Faculdade de Filosofia, Letras e Ciências Humanas (FFLCH-USP), é mestre pela mesma instituição e cursou Teatro na Escola de Arte Dramática (EAD). O diretor brasileiro escolheu a obra $A$ hora da estrela, de Clarice Lispector, para trabalhar com os alunos da UNAM, que em sua nova versão foi intitulada Rodrigo S.M..

Na opinião de Mario Espinosa, os diretores fizeram trabalhos muito diferentes. "Pedro Mantovani, diretor brasileiro, decidiu adaptar uma novela que é um clássico no Brasil e com um ponto de vista bastante particular fez uma montagem que pode ser considerada de denúncia social. Villarreal, por outro lado, prefere não dirigir obras de terceiros, mas escrever seu próprio texto”.

Os alunos do CUT apresentaram 40 vezes a obra Rodrigo S.M., sendo que os estudantes da EAD e do CAC escolhidos para encenar La pasión en la materia apresentaram a peça somente durante o festival da UNAM. Mario Espinosa explica como sucedeu a dinâmica com o grupo brasileiro: "O espetáculo, que não teve uma vida tão longa, foi dado como morto pelos atores, que apresentaram no Brasil uma mescla da obra e de suas experiências. Sem dúvida, a característica peculiar do mundo criativo de Alberto também teve grande importância nesse processo, do qual ele participou”. 


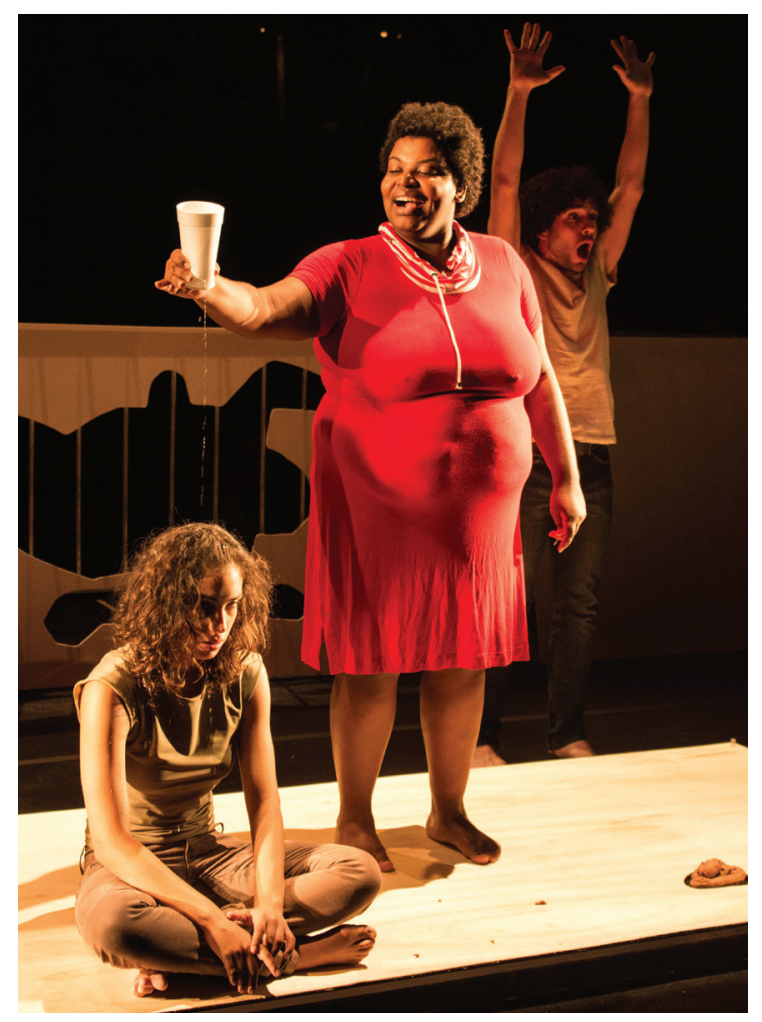

Figura 3 - Adaptação do espetáculo La pasión en la materia em apresentação no Brasil.

Para Mario, o processo de ensaios, executado na Cidade do México por ambas as equipes, teve papel fundamental no sentido de romper com as expectativas de todos: diretores, estudantes e escolas, o que permitiu que as obras se desenvolvessem com naturalidade em um contexto posterior às primeiras apresentações no Festival de Teatro Universitário da UNAM. Ele acredita que, ao respeitar-se o modelo de trabalho de cada escola, de cada diretor e de cada grupo de estudantes, foi possível atingir um resultado mais fiel à cultura de ambas as universidades.

\section{POR DETRÁS DAS CORTINAS}

Sol Sánchez, atriz que acabou de concluir seus estudos no CUT, protagonizou o espetáculo Rodrigo S.M. como Macabea. A jovem de 25 anos se lembre do primeiro contato que ela e seus companheiros tiveram com o texto, quando finalmente começaram a trabalhar com Pedro Mantovani, sem nunca antes ter estado no Brasil ou sequer conhecer a autora Clarice Lispector. A montagem foi feita diretamente do México na presença do diretor brasileiro. Para ela, a experiência começou "um pouco às cegas": "Pedro nos apresentou o texto e fizemos um grande trabalho de decifrá-lo. Sua ideia não era nos informar sobre quem era Macabea ou detalhar aspectos do contexto histórico. Ele queria buscar a parte mais social, a crítica que acredita estar presente no texto". De acordo com a atriz, foi possível trabalhar com a obra "porque nem Macabea nem sua história são só brasileiras, esse é um texto que poderia ser representado em qualquer parte do mundo". Sobre a construção do texto, Daniela de los Ríos conta que trabalhar na adaptação de uma narrativa que não foi originalmente pensada para o teatro também foi uma experiência muito enriquecedora. "Quando terminamos de ler a novela, esperávamos que Pedro fosse apresentar para a gente o texto dramático, mas não existia tal. Então, criamos um roteiro teatral, foi um processo muito interessante".

Para Sol, a chance de visitar o Brasil ajudou a completar o processo de entendimento de certas correspondências culturais: "Muitas coisas nós não entendíamos, Pedro nos falava do preconceito social contra o nordestino e a gente tentava comparar com o caso mexicano do preconceito que existe contra o índio, mas outros detalhes eram ainda mais complicados. No México, quando a personagem de Daniela dizia em espanhol que era 'carioca de pura sepa' o público ficava se perguntando o que era 'carioca'; só no Brasil essa expressão tem sentido, como também, referir-se ao sertão de Alagoas. São aspectos que dependem de referenciais que nós não tínhamos muito claros”. No entanto, ela revela que a essência, a matéria viva do texto, sempre lhe pareceu muito humana.

$\mathrm{Na}$ opinião do ator Marco Guagnelli, "os povos nativos do México são em sua grande maioria discriminados pela cultura cosmopolita, o que fez o público mexicano reconhecer o personagem de Macabea nem tanto pelo indígena, mas pelas 


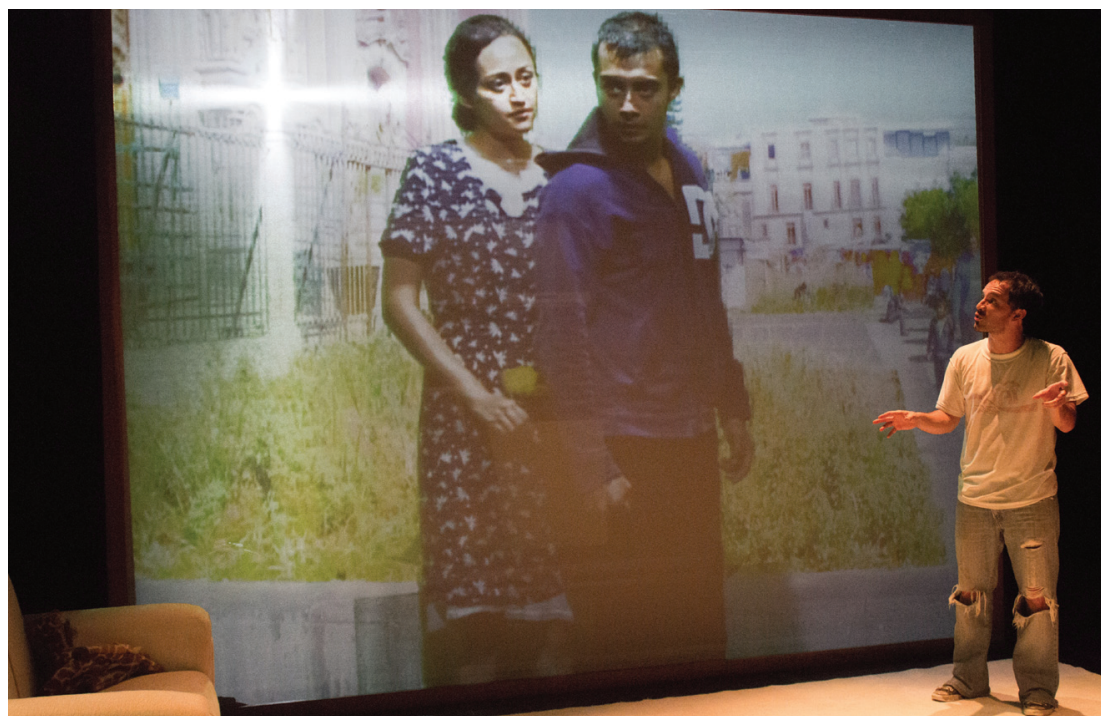

Figura 4 - Como na obra original de Clarice Lispector, Macabea vê sua história narrada em tom de crítica, burla e esquecimento.

pessoas de classe baixa, camada excluída nas sociedades latino-americanas". Marco conta ainda que as plateias dos dois países reagiram de maneira particular ao espetáculo, "a obra era muito comovente no México, as pessoas choravam, viam-se refletidas na personagem de Macabea, mas tinham também aqueles que riam dela e expressavam o mesmo preconceito que tem o co-protagonista, seu namorado, Olímpico". Para Sol, "no México, às vezes se passava um melodrama a mais, sendo que no Brasil a reação da maioria era de indignação e revolta”. Sobre esse ponto, Marco argumenta que "uma das razões para a crítica brasileira ser mais evidente é a proximidade com o referente cultural, o fato de terem consciência do papel do nordestino".

Apresentado em espanhol para os espectadores brasileiros na Tenda Cultural Ortega y Gasset (equipamento cultural da Universidade de São Paulo), Rodrigo S.M. ganhou o público por sua expressividade. Como personagem colocado em posição de observação, Marco lembra dos momentos em que viu a plateia ter que escolher para onde direcionaria sua atenção. "Sendo aquele que confrontava o público me dei conta de que as pessoas às vezes se decidiam por ver a ação, sendo que também faziam suas pausas para ler a legenda. Mas, tratando-se de uma história conhecida pela maioria dos brasileiros, o que acontecia é que muitos optavam por prestar atenção à performance e não ao texto", o que considera bastante satisfatório como ator. "Foi enriquecedor para nós, porque percebemos como os atores podem ser tão completos como o são as palavras".

No caso da obra La pasión en la materia, o processo de montagem aconteceu de forma diferente. Ao invés de o diretor mexicano se deslocar para o Brasil a fim de trabalhar com os atores, todo o grupo foi até o México se preparar para as apresentações do Festival de Teatro Universitário da UNAM, ocasião em que ambos os espetáculos estrearam. Segundo Darília Lilbé, "estar no país durante um mês foi muito válido por permitir a aproximação com outra cultura". Para ela, a disponibilidade para o trabalho no México é muito interessante.

A atriz cita as especialidades desempenhadas pelos funcionários mexicanos como um ponto positivo na elaboração da peça e diz ter se surpreendido com a preocupação de Alberto em também cuidar de pequenos detalhes. "No palco, dispúnhamos de alguns objetos, como tablados e cadeiras, e era curioso ver como ele media a distância entre cada um deles. Se tivessem centímetros a mais ou a menos entre uma cadeira e outra, o Alberto via de longe", completa.

Além disso, Darília cita a questão de apresentar 
Figura 5 - "A partir do momento em que dou o meu corpo para ser pichado, a plateia precisa tomar uma decisão: de sair, de pintar o próprio corpo ou de continuar sentada. O público precisa assumir um ponto de vista. Não estamos criticando sua forma de se colocar, apenas queremos que se coloquem", Darília Lilbé sobre o encerramento da peça.

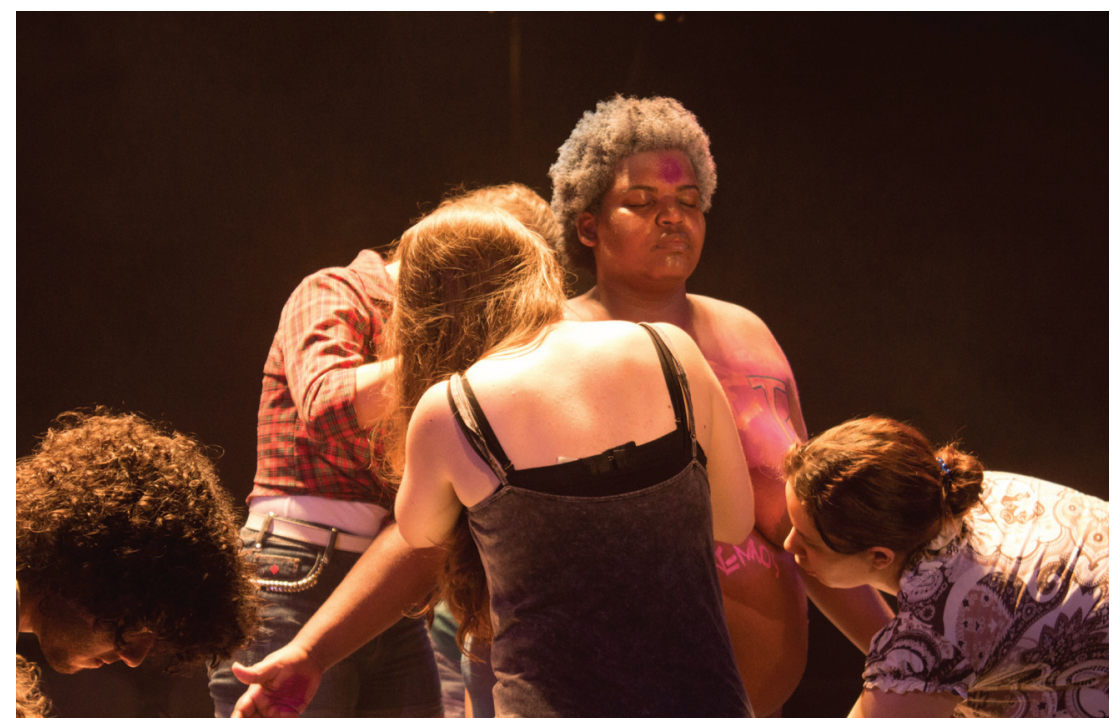

a peça em português para um público que fala espanhol como outro dos desafios que viveu junto de seus companheiros de palco. "Às vezes você termina a cena e se pergunta: Ele entendeu? Não. Ok. Apesar da legenda, essa troca foi muito importante. Muita gente assistia ao espetáculo duas ou até três vezes: a primeira, acho que só para ver o que era, depois uma só para ler e a terceira só para ver. Nós não contamos uma história, são muito mais provocações. Mas também tiveram aqueles que assistiram só uma vez e falaram: odiei ou adorei”.

Sobre as diversas reações ao final do espetáculo, ela compara a reação do público mexicano à da plateia brasileira: "A peça terminava comigo sendo pichada tanto no México, como no Brasil. Acho que nós, brasileiros, estamos muito acostumados com o aplauso ou o black-out, então, terminar uma peça onde acontece uma performance e essa performance simplesmente se mantém, se mantém, se mantém... não é algo comum. No Brasil, as pessoas ficavam sem saber se podiam se retirar. No México, aconteceu a performance, tocaram duas, três, quatro músicas e acabou. Acabou”.

Foi também em meio a essa experiência que ela se deu conta da importância de discutir seu papel em cena como atriz negra, principalmente por estar em um país em que o preconceito está dirigido a outros setores sociais. "Questionei meu papel como negra, mas eu nem poderia imaginar isso antes”. De acordo com ela, a Darília que fez A paixão da matéria, ela existe, mas está muito diferente. "Meus companheiros de cena também mudaram muito e até por isso a apresentação que fizemos no Brasil foi outra. Nem pior, nem melhor. Mais sincera”.

A atriz lembra ainda que essas adaptações acompanhadas pelo diretor, para inserir o enredo em um novo contexto de experiências dos atores - foram importantes também para que a peça não tivesse uma leitura racista, "até porque ela não tem uma leitura racista”, como ressalta Darília. Por não estar igualada aos outros atores (de perfis muito semelhantes) no palco e funcionar como uma espécie de personagem a que ela mesma se refere como "verbo de ligação" entre as diferentes cenas, o grupo temia que o público brasileiro ficasse com a impressão de que tinha algo errado acontecendo. De acordo com a atriz, "essa é a nossa ferida" e, "talvez, se em seu lugar estivesse um índio, a reação, no México, pudesse ser parecida, como de: 'oh, tem alguma coisa aí que é diferente, o curso dessa personagem, ela não está igualada aos outros atores"'. 


\section{SIGNOS E SÍMBOLOS}

Troca de experiências importante para as duas partes, o intercâmbio cultural estabelecido entre a USP e a UNAM gerou mais do que uma cooperação acadêmica positiva. Sobre o processo de produção e os resultados obtidos com ambas as peças teatrais, Mario Espinosa comenta:

"No Brasil, Clarice Lispector é leitura quase obrigatória, o que dispensa a necessidade de se ver as letras. As pessoas sabem e querem ver o que está acontecendo [...] No México, o espetáculo é uma surpresa. E não importa se no México a obra de Villarreal foi apresentada de maneira distinta, porque o assunto do racismo também é interpretado de maneira distinta. Lá os espectadores se emocionavam, pintavam, aplaudiam e abraçavam os atores [...] No Brasil, ficaram muito surpresos. Sem saber se era bom se levantar ou não; pintar ou não”.

E conclui:

"O teatro por um lado é universal, mas por outro é um fenômeno local, sendo que alguns signos e símbolos podem ser entendidos por todos e outros são de lugar. Mas a partir daí, como explicar que uma mesma obra possa ter um contato tão diferente com os espectadores? Isso, acima de tudo, me parece apaixonante".

NOTA: A estreia das obras Rodrigo S.M. e La pasión en la materia aconteceu em fevereiro de 2013 no México, sendo que as obras foram reapresentadas no Brasil em dezembro. De acordo com Ferdinando Martins, a USP e a UNAM têm convênio firmado até 2015. O convênio prevê a realização de atividades variadas que perpassam não só pelo universo do teatro, como também do cinema, da literatura e da sexualidade; tudo em concordância com o cronograma de eventos previsto para os próximos anos nas duas instituições.

\section{FICHA TÉCNICA}

\section{La pasión en la materia}

Autor, Diretor, Iluminação e Cenário: Alberto Villarreal

Elenco: Elton Santos, Juliana Prado, Juliana Spinola, Renan Dias e Darília Lilbé

Produção: Teatro UNAM/ TUSP/ Tenda Cultural Ortega y Gasset

\section{Rodrigo S.M.}

Direção e Adaptação: Pedro Mantovani

Elenco: Guillermo Revilla, Óscar Serrano, Ximena

Sastrias, Marco Guagnelli, Daniela de los Ríos e Sol Sánchez

Produção: Centro Cultural Universitario/ UNAM/ TUSP / Tenda Cultural Ortega y Gasset

Fotos: Mariana Maziero/Tenda Cultural Ortega y Gasset

MARINA SALLES graduanda em Jornalismo da Escola de Comunicações e Artes da Universidade de São Paulo (ECA-USP) e repórter para o volume 11 da Revista Cultura e Extensão USP -e-mail:marina.salles.jor@gmail.com 